\title{
Análise multicritério aplicada à escolha de oleaginosas para a produção de biodiesel
}

O uso de fontes alternativas de energia vem ganhando muita força devido ao aumento da preocupação com as questões ambientais, sociais e econômicas. Um exemplo disso é a utilização dos biocombustíveis derivados de óleos e gorduras de origem animal ou vegetal, que surgem como uma promessa para substituição do óleo diesel, com especial destaque para o biodiesel. O biodiesel representa uma nova opção geradora de energia dentro do setor energético brasileiro. Um combustível renovável, de qualidade comprovada que vai ajudar na redução da dependência do diesel de petróleo. Atuando, também, no desenvolvimento do agronegócio, buscando atingir dessa forma todos os membros da cadeia de produção do biodiesel. A seleção de matérias-primas para produção de biodiesel geralmente envolve situações de conflito de interesses no processo de gestão. Para ajudar na resolução recomendasse um conjunto de ferramentas capazes de gerenciar conflitos como os métodos de Apoio Multicritério à Decisão (AHP, MACBETH, SMART, ELECTRE, PROMETHEE, MODM, etc.). Este artigo tem por finalidade analisar, através de metodologia multicritério, qual das culturas ou espécies oleaginosas é mais apropriada para produção de biodiesel. Para isso foi utilizado os métodos da família PROMETHEE (I, II e GAIA), que ordenam as alternativas de acordo com os critérios estabelecidos em fluxos líquidos de sobre classificação parciais e totais. A representação do sistema de escolha se deu pelo exercício da criação e posterior comparação de dois cenários: um de base e outro mais abrangente, cada um levando em conta as alternativas (dendê, canola, soja, etc.) e critérios (conteúdo médio de óleo, meses de colheita, custos de produção, etc.) próprios. A ordenação final do resultado gerado na análise multicritério no cenário 1 foi: dendê; soja; canola; mamona e amendoim. Enquanto no cenário 2: dendê; canola; soja; girassol; amendoim; babaçu e mamona.

\section{Multicriteria analysis applied to the choice of oilseeds for the production of biodiesel}

\begin{abstract}
The use of alternative energy sources has gained a lot of strength due to increased concern about the environmental, social and economic issues. An example is the use of biofuels derived from fats and oils of animal or vegetable origin, arising as a promise to replace diesel oil, with special emphasis on biodiesel. Biodiesel represents a new option for generating energy within the Brazilian energy sector. A renewable fuel, proven quality that will help reduce dependence on petroleum diesel. Also working on the development of agribusiness, thereby seeking to reach all members of the chain of production of biodiesel. The selection of raw materials for biodiesel production generally involves situations of conflict of interest in the management process. To assist in the resolution, it was recommend a set of tools capable of managing conflicts such as Multicriteria Decision Support (AHP, MACBETH, SMART, ELECTRE, PROMETHEE, MODM, etc.). This article aims to analyze through multicriteria methodology which culture or oilseeds species is more suitable for biodiesel production. For this, the methods of the family PROMETHEE (I, II and GAIA) were used, which order the alternatives according to the criteria established in partial and total net over classification flows. The representation of the system of choice was based on the exercise of the creation and subsequent comparison of two scenarios: a of base and one more comprehensive, each taking into account the alternatives (palm, rapeseed, soy, etc.) and criteria (medium oil content, harvest months, production costs, etc.) own. The final ordering of the result generated in the multicriteria analysis in scenario 1 was: palm; soy; rapeseed; castor bean and peanut. While in scenario 2: palm; canola; soy; sunflower, peanut, babassu and castor bean.
\end{abstract}

Keywords: Energy; Biodiesel; Multicriteria.

Topic: Desenvolvimento, Sustentabilidade e Meio Ambiente

Reviewed anonymously in the process of blind peer.
Received: $10 / 06 / 2018$ Approved: $24 / 07 / 2018$
Genilson do Nascimento Carvalho Júnior (it) Universidade Federal Fluminense, Brasil http://lattes.cnpq.br/5719009888601411 http://orcid.org/0000-0002-1378-2238 genilson.carvalho.junior@gmail.com

Roberto Guimarães Pereira (10

Universidade Federal Fluminense, Brasil http://lattes.cnpq.br/9607255646013062 http://orcid.org/0000-0001-6094-1396 temrobe@vm.uff.br
Referencing this:

CARVALHO JÚNIOR, G. N.; PEREIRA, R. G.. Análise multicritério aplicada à escolha de oleaginosas para a produção de biodiesel. Revista Ibero Americana de Ciências Ambientais, v.9, n.5, p.231-247, 2018. DOI: http://doi.org/10.6008/CBPC2179-6858.2018.005.0021

DOI: 10.6008/CBPC2179-6858.2018.005.0021 


\section{INTRODUÇÃO}

A substituição dos combustíveis fósseis tem sido motivada por fatores ambientais, econômicos e sociais, uma vez que toda a sociedade depende de seu uso. Nesse contexto, uma alternativa que se tem destacado é o uso de biocombustíveis. Pode-se definir biocombustível como todo produto útil para a geração de energia, obtido total ou parcialmente de biomassa. Na tabela 1 são apresentados exemplos de biocombustíveis com matérias primas, processos de obtenção e composições químicas dos mesmos:

Tabela 1: Biocombustíveis.

\begin{tabular}{|l|l|l|l|}
\hline Biocombustível & Matéria prima & Processos de obtenção & Composição química \\
\hline Carvão vegetal & Madeira & Pirólise & Carbono (C) \\
\hline Álcool & $\begin{array}{l}\text { Açúcares (glicose, amido, } \\
\text { celulose, etc) }\end{array}$ & Fermentação anaeróbica & Etanol $\left(\mathrm{CH}_{3} \mathrm{CH}_{2} \mathrm{OH}\right)$ \\
\hline Biogás & Todo tipo de biomassa & Fermentação anaeróbica & Hidrocarbonetos leves \\
\hline Biogás de síntese & Biomassa em geral & Gaseificação & $\begin{array}{l}\text { Mistura de vários gases, } \\
\text { essencialmente } \\
\left.\text { (CO e } \mathrm{H}_{2}\right)\end{array}$ \\
\hline Biodiesel & Óleos e gorduras & Esterificação ou transesterificação & Monoésteres de ácidos graxos \\
\hline Bio-óleo & Óleos e gorduras & $\begin{array}{l}\text { Mistura de hidrocarbonetos e } \\
\text { compostos } \\
\text { oxigenados }\end{array}$ \\
\hline
\end{tabular}

Fonte: Adaptado de Oliveira et al. (2008).

O Programa Nacional de Produção e Uso de Biodiesel (PNPB) lançado oficialmente em 6 de dezembro de 2004, surgiu como uma forma de uniformizar as informações e difusão do conhecimento, a ideia central é fazer com que todos os benefícios gerados pelo programa cheguem a todos os membros da cadeia produtiva do biodiesel. Dando devido reconhecimento à agricultura familiar e da sua eventual valorização feita através de medidas que vão ajudar a mesma. A captação de crédito e regime tributário segue o modelo do tipo de oleaginosa (amendoim, mamona, canola, etc), tamanho do produtor (pequeno, médio ou grande), região (Norte, Sul, etc) e cada elemento da cadeia vão participar conforme seu campo de atuação (agronegócio e agricultura familiar).

O Brasil está em segundo lugar atualmente no ranking mundial da produção de biodiesel, ficando atrás apenas dos Estados Unidos. De 2014 a 2015, houve um aumento de 15\% na produção nacional desse biocombustível, total de quase 4 bilhões de litros de acordo com a Agência Nacional do Petróleo, Gás Natural e Biocombustíveis (ANP). Lembrando que em 2008 o Brasil era apenas quarto colocado, outro fator que contribuiu para o crescimento do mercado brasileiro de biodiesel é o aumento mandatório e gradativo do percentual de mistura (ver tabela 2).

Tabela 2: Legislação acerca do percentual de mistura compulsória.

\begin{tabular}{|c|c|c|c|c|c|c|c|c|}
\hline $\begin{array}{l}\text { Percentual de } \\
\text { Mistura }\end{array}$ & $2 \%$ & $3 \%$ & $4 \%$ & $5 \%$ & $6 \%$ & $7 \%$ & $8 \%$ & $10 \%$ \\
\hline $\begin{array}{l}\text { Conselho } \\
\text { Nacional de } \\
\text { Política } \\
\text { Energética } \\
\text { (CNPE) - } \\
\text { Data }\end{array}$ & $\begin{array}{l}\text { Resolução } \\
\text { no3 - } \\
\text { (23 de } \\
\text { setembro de } \\
\text { 2005) }\end{array}$ & $\begin{array}{l}\text { Resolução } \\
\text { n-2 - } \\
\text { (13 de } \\
\text { março de } \\
2008)\end{array}$ & $\begin{array}{l}\text { Resolução } \\
n \div 2- \\
\text { ( } 27 \text { de abril } \\
\text { de 2009) }\end{array}$ & $\begin{array}{l}\text { Resolução } \\
\text { n6 - } \\
\text { (16 de } \\
\text { setembro de } \\
\text { 2009) }\end{array}$ & $\begin{array}{l}\text { Medida } \\
\text { Provisória } \\
\mathrm{n} \text { 은 - } \\
\text { ( } 28 \text { de maio } \\
\text { de } 2014 \text { ) }\end{array}$ & $\begin{array}{l}\text { Medida } \\
\text { Provisória } \\
\mathrm{n}=647 \text { - } \\
\text { ( } 28 \text { de maio } \\
\text { de } 2014 \text { ) }\end{array}$ & $\begin{array}{l}\text { Resolução } \\
\text { no3 - } \\
\text { (15 de abril } \\
\text { de 2016) }\end{array}$ & $\begin{array}{l}\text { Resolução } \\
\text { n-23 - } \\
\text { (9 de } \\
\text { novembro } \\
\text { de 2017) }\end{array}$ \\
\hline $\begin{array}{l}\text { Data de } \\
\text { Aplicação }\end{array}$ & $\begin{array}{l}1 \text { de janeiro } \\
\text { de } 2006\end{array}$ & $\begin{array}{l}1 \text { de julho } \\
\text { de } 2008\end{array}$ & $\begin{array}{l}1 \text { de julho } \\
\text { de } 2009\end{array}$ & $\begin{array}{l}1 \text { de janeiro } \\
\text { de } 2010\end{array}$ & $\begin{array}{l}1 \text { de julho } \\
\text { de } 2014\end{array}$ & $\begin{array}{l}1 \text { de } \\
\text { novembro } \\
\text { de } 2014\end{array}$ & $\begin{array}{l}23 \text { de } \\
\text { março de } \\
2017\end{array}$ & $\begin{array}{l}1 \text { de março } \\
\text { de } 2018\end{array}$ \\
\hline
\end{tabular}

Fonte: Adaptado de Alvarenga (2013). 
O biodiesel é um combustível biodegradável derivado de fontes renováveis, que pode ser produzido a partir de gorduras animais (sebo de boi, banha de porco, gordura de frango, óleos de peixes, etc) ou de óleos vegetais, existindo dezenas de espécies vegetais no Brasil que podem ser utilizadas, tais como mamona, dendê, girassol, canola, gergelim, soja, dentre outras. Também, é possível preparar o biodiesel a partir de resíduos industriais ou domésticos, como as sobras de frituras e sabões produzidos no refino do óleo de soja, por esse motivo a energia gerada pelo biodiesel é dita renovável. Substitui total ou parcialmente o óleo diesel de petróleo em motores automotivos (caminhões, tratores, automóveis, etc) ou estacionários (geradores de eletricidade, calor, etc). O processo inicia-se misturando a matéria prima de origem animal ou vegetal com um álcool (metanol ou etanol) e catalisadores que podem ser ácidos, básicos ou enzimáticos.

No Brasil o biodiesel deve atender às especificações de qualidade da ANP em sua resolução No. 45 de 25.08.2014. Pode ser usado puro ou misturado ao diesel em diversas proporções, o percentual de biodiesel misturado ao diesel é indicado pelo número após a letra B (blend-mistura). A mistura de $2 \%$ de biodiesel ao diesel de petróleo é chamada de B2 e assim sucessivamente, até o biodiesel puro, denominado B100. A Lei federal 11.097/2005 que introduziu o biodiesel determinou aumentos consecutivos na mistura com o diesel, delegando competência à ANP para regular e fiscalizar a comercialização de biocombustíveis. Atualmente o percentual é de 10\% (B10) iniciado em março de 2018, consoante ao texto da Lei № 13.263 de 23 de março de 2016.

O Apoio Multicritério à Decisão (AMD) visa direcionar por meio da recomendação de ações a 'pessoa' que vai tomar a decisão (decisor), funcionando como ferramenta de apoio no processo de gestão. O AMD busca não pregar uma verdade absoluta, mas um conjunto de oportunidades montado e interpretado pelos analistas, evidenciado na figura de um modelo matemático. O biodiesel representa a busca por uma mudança de postura perante a discussão sobre as questões ambientais, sociais e econômicas através de alternativas mais sustentáveis. A tabela 3 revela exemplos de fatores econômicos, sociais e ambientais na escolha da oleaginosa.

Tabela 3: Fatores econômicos, sociais e ambientais.

\begin{tabular}{|l|l|l|}
\hline Fatores & \multicolumn{2}{l|}{} \\
\hline Econômico: & Social: & Ambiental: \\
\hline Produtividade agrícola & Custo da terra & Grau de mecanização \\
\hline Teor de óleo no grão & Empregabilidade & Esgotamento do solo \\
\hline Custo de produção & Manejo da cultura & Demanda hídrica \\
\hline
\end{tabular}

Fonte: Adaptado de Khalil (2006).

Esses fatores podem ser usados como exemplos de critérios nos métodos de apoio à decisão. Na tabela 4 é mostrada a potencialidade de matérias-primas (oleaginosas e gordura animal) brasileiras por região geográfica. As variedades de oleaginosas apresentadas na tabela acima podem ser utilizadas nos métodos de apoio à decisão como exemplos de alternativas e diferentes cenários. O presente artigo tem como objetivo principal classificar as culturas utilizadas para a produção de biodiesel industrial por intermédio da análise multicritério. Foi feita uma análise da potencialidade do Brasil na produção de biodiesel, relacionando as fontes principais cultiváveis de biodiesel com os métodos de AMD. 
Tabela 4: Variedades de matérias-primas (oleaginosas e gordura animal) por região.

\begin{tabular}{|l|l|}
\hline Região & Oleaginosas e gordura animal \\
\hline Norte & Dendê; Babaçu; Soja e Gordura animal \\
\hline Centro-Oeste & Soja; Algodão; Girassol; Mamona e Gordura animal \\
\hline Sul & Soja; Colza; Girassol; Algodão e Gordura Animal \\
\hline Nordeste & Babaçu; Soja; Mamona; Dendê; Algodão; Coco e Gordura Animal \\
\hline Sudeste & Soja; Mamona; Algodão, Amendoim e Gordura Animal \\
\hline
\end{tabular}

Fonte: Adaptado de Embrapa (2016).

\section{REVISÃO TEÓRICA}

A tomada de decisão foi definida de forma diferente por vários pesquisadores, Harris (2012) define formalmente a tomada de decisão como "o estudo de identificar e escolher alternativas com base nos valores e preferências dos tomadores de decisão". Segundo Mutikanga et al. (2011), tomada de decisão é "o processo cognitivo que leva à seleção de um curso de ação entre alternativas".

Em 1969, um marco importante para análise de decisão aconteceu durante o VII Simpósio de Programação Matemática, quando Roy apresentou uma seção sobre organização de múltiplos objetivos (Classement et choix en presence de points de vue multiples: la methode ELECTRE). De acordo com Tsoukiàs (2008), outro marco para a teoria de decisão ocorreu em 1976, quando os autores Keeney e Raiffa publicaram um livro (Decision with Multiple Objectives: preferences and value tradeoffs) expandindo a teoria da decisão com a presença de múltiplos critérios.

O Apoio Multicritério à Decisão (AMD) surgiu formalmente como ramo da Pesquisa Operacional (PO) na década de 1970, envolvendo abordagens diferenciadas. No entanto, alguns métodos elementares já existiam desde o século XVIII onde estudos precursores da metodologia multicritério deram origem as duas principais escolas de pensamentos conhecidas até hoje.

Os primeiros estudos formais nesse assunto apareceram após a Revolução Francesa com as publicações de Borda (escola americana) e Condorcet (escola francesa). Estes autores queriam resolver problemas em que várias pessoas opinavam, em especial, na situação da atribuição de penas a réus em um tribunal (BARBA-ROMERO et al., 1997, citado por SOARES DE MELLO et al., 2003).

Para o tão sonhado desenvolvimento sustentável a busca é por uma fonte de energia renovável como a biomassa e seus derivados: Gomes et al. (2013); Chaves et al. (2014); Clímaco et al. (2012); Delai et al. (2014) e Narayanan et al. (2007). Há uma demanda mundial crescente por energias ditas renováveis ou bioenergia, escolher qual tipo utilizar não é uma tarefa fácil. Por isso recomenda-se o uso de alguma ferramenta de gestão como, por exemplo, os métodos multicritérios: Scott et al. (2012); Guardiola et al. (2017); Rabelo et al. (2009); Ferreira et al. (2010); Ren et al. (2013); Newlands et al. (2012); Cardoso et al. (2012) e Castrillón et al. (2017).

A diversificação dos métodos multicritérios se dá através da combinação dos mesmos para resolução de um problema (modelos híbridos), podendo incluir a participação de outros programas para melhorar os resultados encontrados: Gomes (1999) e Corral et al. (2015). Ou devido a sua aplicação em outras áreas do conhecimento sem ter a necessidade de estar somente ligada a área ambiental: Gomes et al. (2015) e Silva et al. (2014). Atualmente, tem-se feito muito uso dos modelos híbridos ou técnicas híbridas dos métodos 
multicritérios para seleção de biocombustíveis, ainda mais quando aborda casos complicados como em Sakthivel et al. (2015) e Nwokoagbara et al. (2015).

Apoiar as decisões é um dos compromissos básicos dos métodos multicritérios. O que acabou contribuindo em um crescente uso da ferramenta multicritério na última década, principalmente nas áreas ambientais, onde o resultado alcançado com uso dos métodos de AMD diferentes envolvendo o mesmo problema não varia significativamente com o método aplicado, gerando classificações semelhantes de alternativas para a gestão ambiental: Huang et al. (2011) e Scott et al. (2012).

\section{METODOLOGIA}

Para Gomes et al. (2004, citado por CARDOSO et al., 2012), as etapas correspondentes aos vários métodos de análise multicritério existentes, cada um com suas particularidades, são: Definição dos atores envolvidos - especialistas (quando for o caso), analistas e decisores; Analista - é a pessoa encarregada de interpretar e quantificar as opiniões dos decisores, estruturar o problema, elaborar o modelo matemático e apresentar os resultados para a decisão. Embora não seja recomendável, pode ser que aconteça do analista ser um dos decisores; Modelo - é o conjunto de regras e operações matemáticas que permitem transformar as preferências e opiniões dos decisores em um resultado quantitativo; Identificação dos tomadores de decisão - os tomadores de decisão são um grupo de pessoas ou uma pessoa que vai decidir qual(is) alternativa(s) é(são) a(s) melhor(es) para solucionar o problema; Formulação do problema - é o problema de 'pesquisa', ou seja, é o que se quer decidir; Determinação das ações ou alternativas - é a criação de ações ou alternativas, representado pelo conjunto de alternativas $\underline{\mathbf{A}}\left(\mathbf{A}=\left\{\mathrm{a}_{1} \ldots \mathrm{a}_{\mathrm{j}} \ldots \mathrm{a}_{n}\right\}\right)$; Elaboração de critérios ou atributos - é a construção de critérios ou atributos, representado pelo conjunto de critérios $\underline{F}\left(F=\left\{g_{1} \ldots g_{j} \ldots g_{m}\right\}\right)$; Avaliação das alternativas - é a criação de uma matriz de avaliações que permite avaliar as alternativas de acordo com cada critério. As linhas correspondem às alternativas e as colunas aos critérios; Determinação de pesos - é a criação de ponderações para cada critério; Agregação dos critérios - é a reunião e ordenamento das alternativas em conformidade com os critérios estabelecidos, ficando a primeira alternativa como a melhor solução para o problema exposto.

Dependendo do método multicritério utilizado algumas dessas etapas podem deixar de existir e outras podem ser acrescentadas, etapas estas específicas ao método selecionado. Roy et al. (1993) definem quatro problemáticas de apoio à decisão e Gartner (2008) afirma que os problemas normalmente se enquadram em um dos quatro tipos apresentados na tabela 5.

As estruturas de preferência (tabela 6 ) são definidas sobre o conjunto $\underline{\mathbf{A}}$ das alternativas. São constituídas por um conjunto de relações binárias $\left(H_{1}, \ldots, H_{N}\right)$ sobre $\underline{A}$, que satisfazem às exigências de exaustividade e exclusão mútua, isto é, dadas duas alternativas a e $\mathbf{b}$ de $\underline{\mathbf{A}}$, existe uma só relação $\mathrm{H}_{\mathrm{i}}$ que se aplica ao par. As quatro relações fundamentais são indiferença (I), preferência estrita (P), preferência fraca (Q) e incomparabilidade (R) (SOARES DE MELLO et al., 2003). 
Tabela 5: Problemáticas de apoio à decisão.

\begin{tabular}{|l|l|l|}
\hline Tipos de problema & Características & Representação \\
\hline Escolha & Seleção de somente uma das alternativas & $\alpha$ \\
\hline Triagem ou alocação em classes & Escolha de todas as boas alternativas, podendo ser ordenadas ou não & $\beta$ \\
\hline Classificação ou ordenação & Escolha de algumas das melhores alternativas & $\gamma$ \\
\hline Descrição ou cognição & Descrição das alternativas e suas consequências & $\delta$ \\
\hline
\end{tabular}

Fonte: Adaptado de Vilas Boas (2006).

Tabela 6: Estruturas de preferência das alternativas.

\begin{tabular}{|l|l|l|}
\hline Estruturas de Preferência & Representação & Descrição \\
\hline Indiferença & a I b & $\begin{array}{l}\text { Significa que há razões que justificam a indiferença na escolha entre as duas } \\
\text { alternativas. }\end{array}$ \\
\hline Preferência estrita & a P b & $\begin{array}{l}\text { Representa a existência de fatores que provam o favorecimento da alternativa a } \\
\text { em relação à alternativa } \mathbf{b} .\end{array}$ \\
\hline Incomparabilidade & a Q b & Demonstra a existência de dúvida entre a I b e a P b. \\
\hline
\end{tabular}

Fonte: Adaptado de Soares de Mello et al. (2003).

A escolha de qual método de AMD que será utilizado deve ser feita em função do tipo de problema de decisão que se tem em mãos. O conjunto de critérios usados em uma determinada situação de decisão deve satisfazer três condições (conhecidas como axiomas de Roy) para ser uma família coerente de critérios. Em Gomes et al. (2007) esses axiomas em linguagem não matemática são: Exaustividade - impõe a necessidade de descrever o problema levando em conta todos os aspectos relevantes; Coesão - obriga à correta análise de quais são os critérios de maximização e quais os de minimização; Não Redundância - obriga a excluir critérios que avaliem características já consideradas por outro critério. Segundo Vilas Boas (2006), depois de obter as preferências do decisor efetua-se a agregação, definindo o tipo de método multicritério de apoio à decisão a ser aplicado. Com base no procedimento de agregação das preferências, classificam os AMD em três tipos (ver tabela 7).

Tabela 7: Métodos de agregação das preferências.

\begin{tabular}{|l|l|l|}
\hline I) Métodos de agregação a um critério único de síntese & II) Métodos de subordinação ou outranking & III) Métodos interativos \\
\hline UTA & QUALIFLEX & MODM \\
\hline PREFCALC & ORESTE & - \\
\hline UTASTAR & MELCHIOR & - \\
\hline MINORA & PROMETHEE & - \\
\hline AHP & TACTIC & - \\
\hline MACBETH & MAPPAC & - \\
\hline MAVT & PRAGMA & - \\
\hline SMART & N-TOMIC & - \\
\hline EVAMIX & ELECCALC & - \\
\hline TOPSIS & ELECTRE I, II, III e IV & - \\
\hline- & MERCHIOR & - \\
\hline- & REGIMA & - \\
\hline- & NAIADE & - \\
\hline
\end{tabular}

Os problemas que envolvem a seleção de matérias-primas (de origem animal ou vegetal) para produção de biodiesel encontrado em artigos sobre biocombustíveis geralmente utilizam os métodos de subordinação ou outranking. Por causa disso, apesar dos diversos métodos de AMD existentes, neste artigo foi escolhida a utilização da metodologia PROMETHEE (Preference Ranking Organization Method for Enrichment Evaluation). Outro fator importante que pesou, também, na escolha desse método é a facilidade de obtenção do programa na versão básica (Software de Análise Multicritério Visual PROMETHEE 1.4 - 
Academic Version), necessário para rodar o modelo, um arquivo leve e executável sem necessidade de instalação obrigatória no computador para funcionar.

Os métodos PROMETHEE têm como objetivo proporcionar aos decisores um melhor entrosamento e entendimento da metodologia de apoio à decisão utilizada. Ele atua na construção de relações de superação valorizadas, incorporando conceitos e parâmetros que possuem alguma interpretação física ou econômica facilmente compreensível pelo decisor (GARTNER, 2008).

Esta abordagem faz uso abundante do conceito de pseudocritério (que permite integrar explicitamente elementos mal definidos ou conhecidos com uma margem de imprecisão), construindo o grau de superação entre cada par de ações ordenadas levando em conta a diferença de pontuação que essas ações possuem a respeito de cada atributo (FLAMENT, 1999, citado por VILAS BOAS, 2006).

Em PROMETHEE I se obtém um ordenamento parcial ( $\Phi+, \Phi-)$, no PROMETHEE II pode-se obter um ordenamento completo $(\Phi)$ considerando os fluxos líquidos de cada alternativa. Outras variantes do método analisam situações mais sofisticadas de decisão, em particular problemas com um componente estocástico. Dessa forma se desenvolveram as versões PROMETHEE III, PROMETHEE IV, PROMETHEE V (FLAMENT, 1999, citado por VILAS BOAS, 2006). E PROMETHEE GAIA - extensão dos resultados do PROMETHEE, através de um procedimento visual e interativo. Para Morais et al. (2006) a utilização do PROMETHEE II exige o conhecimento de alguns conceitos:

$\mathbf{w}_{\mathbf{j}}$ - é o peso do critério $\mathbf{j}$;

$g_{j}(a)$ - é o valor da alternativa a no critério j;

$\mathbf{q}$ - limite de indiferença, o maior valor para $\left[\mathbf{g}_{\mathbf{j}}(\mathbf{a})-\mathbf{g}_{\mathbf{j}}(\mathbf{b})\right]$ abaixo do qual existe uma indiferença;

$\mathbf{p}$ - limite de preferência, o menor valor para $\left[\mathbf{g}_{\mathbf{j}}(\mathbf{a})-\mathbf{g}_{\mathbf{j}}(\mathbf{b})\right]$ acima do qual existe uma preferência estrita;

o modelo de critério verdadeiro é definido quando $\mathbf{p}=\mathbf{q}=0$, pseudocritério fica $\mathbf{p} \geq 0$ e $\mathbf{q} \geq 0$, semicritério onde $\mathbf{p}=\mathbf{q}$ e o pré-critério onde $\mathbf{q}=0$;

$F_{j}(a, b)$ - é a função de preferência, valor que varia de 0 a 1 e representa o comportamento do decisor frente as diferenças provenientes da comparação par a par entre as alternativas, para um dado critério, indicando a intensidade da preferência da diferença $\mathbf{g}_{\mathbf{j}}(\mathbf{a})$ - $\mathbf{g}_{\mathbf{j}}(\mathbf{b})$ (BRANS et al. 2002).

$\Pi(\mathbf{a}, \mathbf{b})$ é o grau de sobreclassificação de $\mathbf{a}$ em relação $\mathbf{a} \mathbf{b}$, também chamado de intensidade de preferência multicritério. É calculado por:

$$
\boldsymbol{\Pi}(\boldsymbol{a}, \boldsymbol{b})=\frac{1}{W} \sum_{j=1}^{n} w_{j} F_{j}(a, b) \quad \text { sendo, } \boldsymbol{W}=\sum_{j=1}^{n} w_{j}
$$

$\Phi^{+}(a)$ é o fluxo de saída e representa a média de todos os graus de sobreclassificação de a, com respeito a todas as outras alternativas. É dado pela expressão:

$$
\boldsymbol{\Phi}^{+}(\boldsymbol{a})=\sum_{b \in A} \frac{\Pi(a, b)}{n-1}
$$

Quanto maior $\Phi^{+}(a)$, melhor a alternativa e mostra o quanto uma ação é preferida à outra. 
$\Phi^{-}($a) é o fluxo de entrada, representa a média de todos os graus de sobreclassificação de todas as outras alternativas sobre a. É dado pela expressão:

$$
\boldsymbol{\Phi}^{-}(\boldsymbol{a})=\sum_{b \in A} \frac{\Pi(b, a)}{n-1}
$$

Quanto menor $\Phi^{-}(a)$, melhor é a alternativa e representa quanto uma ação é preterida por outra.

$\Phi(a)$ é o fluxo líquido de sobreclassificação e representa o balanço entre o poder e a fraqueza da alternativa. É dado pela expressão:

$$
\begin{aligned}
& \boldsymbol{\Phi}(\boldsymbol{a}) \\
& =\Phi^{+}(a)-\Phi^{-}(a)
\end{aligned}
$$

Quanto maior $\Phi(a)$, melhor a alternativa.

O procedimento PROMETHEE deve ser associado com uma função de preferência (tabela 8), a cada critério para comparação por pares. Embora cada decisor esteja examinando os mesmos critérios (podendo associar pesos diferentes), a seleção da função de preferência pode ser feita de forma globalizada ou individual.

Tabela 8: Formas das funções de preferência.

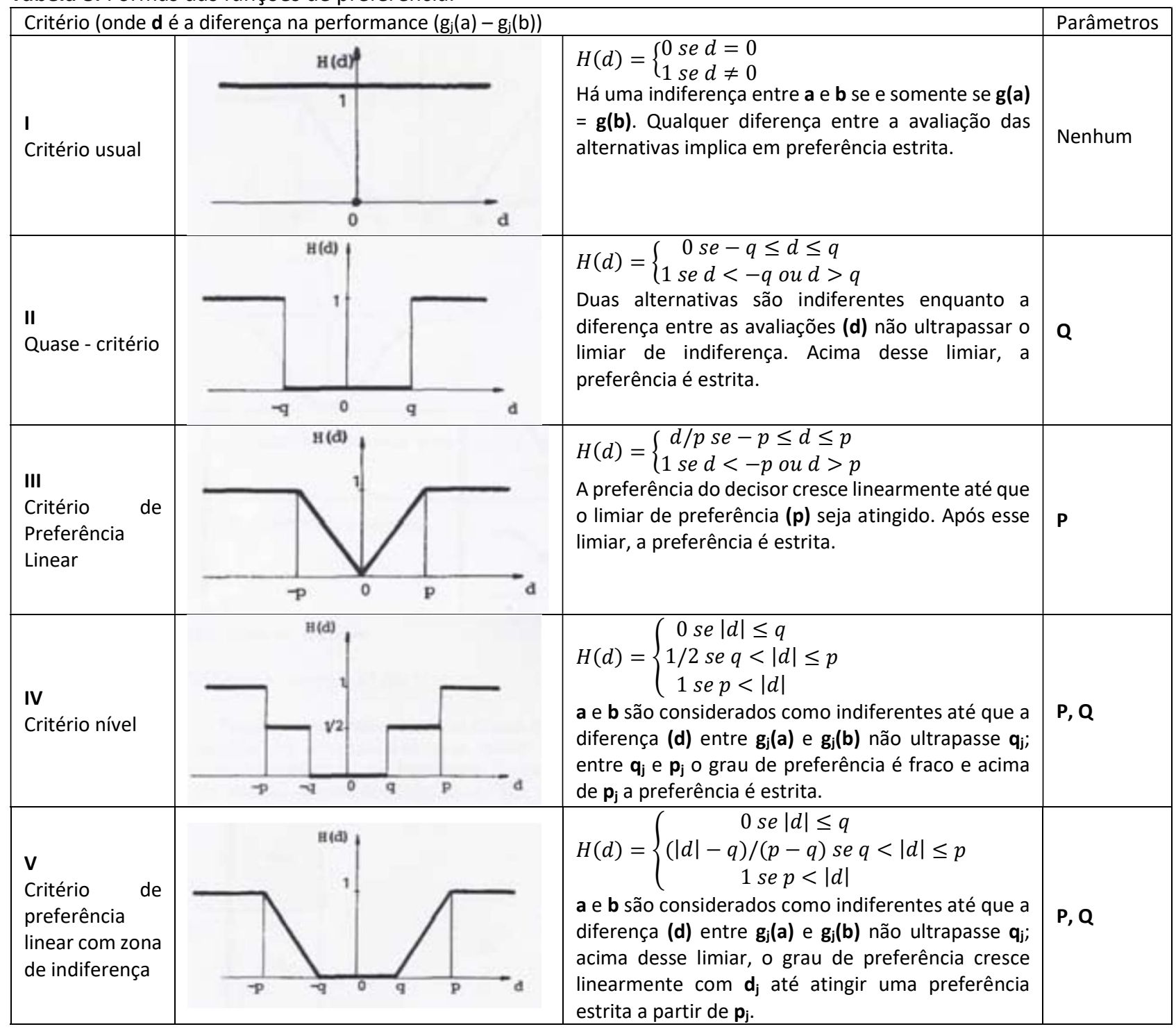




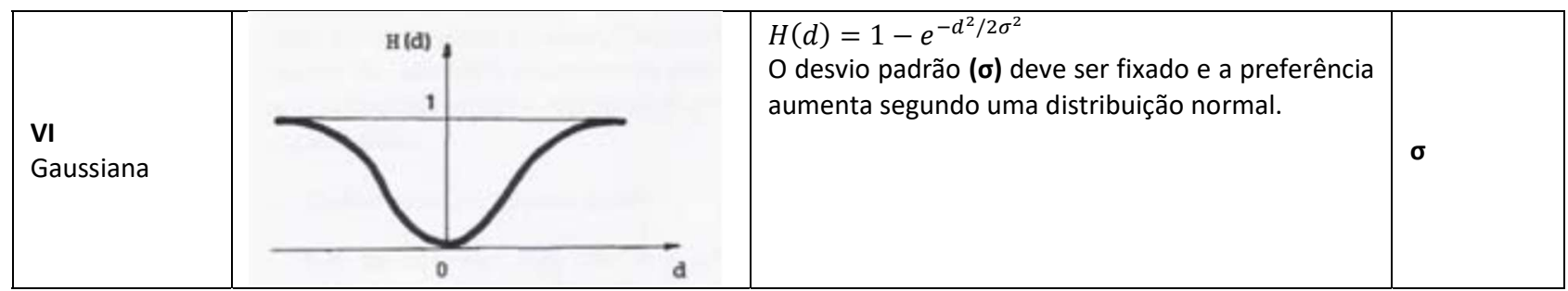

Fonte: Adaptado de Brans et al. (1986, citado por MORAIS et al., 2006).

É importante definir com clareza quem são as alternativas e critérios envolvidos para resolução do problema multicritério. Os critérios correspondem a alguns aspectos relevantes na produção das oleaginosas selecionadas, que podem influenciar indiretamente ou diretamente em alguns casos o custo de produção do biodiesel. Sendo ainda possível em alguns métodos de AMD a utilização de vários cenários diferentes para simular uma dada situação envolvendo a 'vontade' do decisor (avaliação individual) ou grupo de decisores (avaliação global). Na tabela 9, tem-se as alternativas que serão utilizadas para composição dos cenários multicritérios e seus respectivos identificadores (os mesmos usados no programa).

Tabela 9: Alternativas de ação.

\begin{tabular}{|l|l|}
\hline Identificador & Alternativa \\
\hline A1 & Dendê \\
\hline A2 & Colza ou Canola \\
\hline A3 & Mamona \\
\hline A4 & Amendoim \\
\hline A5 & Soja \\
\hline A6 & Babaçu \\
\hline A7 & Girassol \\
\hline
\end{tabular}

Na tabela 10, tem-se os critérios considerados para a formação dos cenários devidamente identificados (seguindo a mesma padronização das alternativas), com uma breve explicação sobre cada um deles e otimização recomendada. Foi considerado um peso por critério na especificação da importância relativa dos critérios. Para avaliação, esses critérios serão maximizados ou minimizados de acordo com a necessidade.

Tabela 10: Critérios considerados.

\begin{tabular}{|c|c|c|c|}
\hline Identificador & Critério & Descrição & Otimização \\
\hline C1 & Conteúdo médio de óleo & $\begin{array}{l}\text { A porcentagem de óleo que pode ser encontrado em cada amêndoa ou } \\
\text { grão de oleaginosa. }\end{array}$ & Max ou Min \\
\hline C2 & Meses de colheita & Mostra o número de meses da colheita. & Max ou Min \\
\hline C3 & $\begin{array}{l}\text { Rendimento médio em } \\
\text { óleo }\end{array}$ & Revela o rendimento de óleo em tonelada por hectare. & Max ou Min \\
\hline C4 & Produtividade Média & $\begin{array}{l}\text { Indica quantas toneladas podem ser produzidas da oleaginosa por } \\
\text { hectare }\end{array}$ & Max ou Min \\
\hline C5 & Custos de Produção & $\begin{array}{l}\text { Refere-se ao custo necessário para o cultivo da espécie em dólar por } \\
\text { tonelada. }\end{array}$ & Max ou Min \\
\hline C6 & Preço óleos & $\begin{array}{l}\text { Corresponde ao valor de preços dos óleos utilizados na produção de } \\
\text { biodiesel. }\end{array}$ & Max ou Min \\
\hline C7 & $\begin{array}{l}\text { Demanda por área } \\
\text { cultivada }\end{array}$ & É a extensão de área necessária para cultivo de oleaginosas. & Max ou Min \\
\hline
\end{tabular}

\section{RESULTADOS}

As possíveis alternativas estratégicas são: amendoim; canola; dendê; mamona e soja (tabelas 4 e 9), para o cenário 1 (tabela 11) baseado em Bilich et al. (2006), incluindo algumas considerações adicionais que 
serão discutidas mais a frente. Os critérios utilizados, otimização considerada e respectivos pesos associados estão na tabela 14.

Tabela 11: Alternativas e critérios do Cenário 1

\begin{tabular}{|l|l|l|l|l|l|l|l|}
\hline Espécie & $\begin{array}{l}\text { Origem } \\
\text { do óleo }\end{array}$ & $\begin{array}{l}\text { Cont. } \\
\text { médio de } \\
\text { óleo [\%] }\end{array}$ & $\begin{array}{l}\text { Meses } \\
\text { de } \\
\text { colheita }\end{array}$ & $\begin{array}{l}\text { Rend. } \\
\text { médio em } \\
\text { óleo [t/há] }\end{array}$ & $\begin{array}{l}\text { Prod. } \\
\text { Média } \\
\text { [t/há] }\end{array}$ & $\begin{array}{l}\text { Custos de } \\
\text { Produção } \\
\text { [US\$\$/t] }\end{array}$ & $\begin{array}{l}\text { Preço } \\
\text { óleos } \\
\text { [US\$̦/t] }\end{array}$ \\
\hline $\begin{array}{l}\text { Amendoim (Arachis } \\
\text { Hypogaea) }\end{array}$ & Grão & 45 & 3 & 0,7 & 1,9 & 1300 & 1281 \\
\hline $\begin{array}{l}\text { Colza ou Canola } \\
\text { (Brassicanapus) }\end{array}$ & Grão & 44 & 3 & 0,7 & 2,3 & 650 & 653 \\
\hline $\begin{array}{l}\text { Dendê (Elaeis } \\
\text { Guineensis N.) }\end{array}$ & Amendôa & 26 & 12 & 4,5 & 2,2 & 286 & 450 \\
\hline $\begin{array}{l}\text { Mamona (Ricinus } \\
\text { communis) }\end{array}$ & Grão & 44 & 3 & 0,75 & 1,0 & 720 & 1040 \\
\hline Soja (Glycine max) & Grão & 17 & 3 & 0,4 & 2,3 & 85 & 560 \\
\hline
\end{tabular}

Fonte: Elaborada a partir de Cardoso et al (2012), Embrapa, Conab e Cadernos NAE (citado por BILICH et al. 2006).

Função de preferência: I - Critério usual (caso simplificado considerado o mesmo para todos os critérios). A maioria dos critérios considerados nos cenários 1 e 2 tem naturezas econômicas como mostra Khalil (2006) na tabela 3, ou seja, pertencem a um mesmo grupo de fatores (tabela 12). Por isso foi utilizada essa função de preferência para os critérios considerados.

Tabela 12: Natureza dos critérios escolhidos.

\begin{tabular}{|l|l|}
\hline Fatores Econômicos & Critérios \\
\hline Produtividade agrícola & $\mathrm{C} 2$, C4 e C7 \\
\hline Teor de óleo no grão & $\mathrm{C}$ e C3 \\
\hline Custo de produção & $\mathrm{C} 5$ e C6 \\
\hline
\end{tabular}

Fonte: Elaborado a partir de Khalil (2006).

Tabela 13: Discussão envolvendo os motivos da otimização de cada critério.

\begin{tabular}{|l|l|l|}
\hline Critérios & Otimização & Discussão \\
\hline C2 e C4 & Max & $\begin{array}{l}\text { A maximização é considerada ideal tanto na fase de aumento do número de meses da colheita, } \\
\text { quanto maior esse número melhor para a produtividade média, evitando desperdícios. }\end{array}$ \\
\hline C7 & Min & $\begin{array}{l}\text { Esse critério é o que traz maior debate atualmente, sempre surge o famoso dilema Produção de } \\
\text { Alimentos X Biocombustíveis. Sem entrar no mérito da questão o presente trabalho optou pela } \\
\text { minimização deste critério. }\end{array}$ \\
\hline C1 e C3 & Max & A maximização se faz necessária para buscar o melhor aproveitamento do óleo encontrado e extraído. \\
C5 e C6 & Min & $\begin{array}{l}\text { A minimização se faz necessária para redução dos gastos devido às flutuações econômicas de } \\
\text { mercado, principalmente quando se considera o uso de moedas estrangeiras nas operações de cultivo } \\
\text { e compra de óleos. }\end{array}$ \\
\hline
\end{tabular}

Tabela 14: Critérios, otimização e pesos do cenário 1.

\begin{tabular}{|l|l|l|}
\hline Critérios & Otimização & Pesos associados \\
\hline C1 & Max & 3 \\
\hline C2 & Max & 1 \\
\hline C3 & Max & 6 \\
\hline C4 & Max & 7 \\
\hline C5 & Min & 9 \\
\hline C6 & Min & 10 \\
\hline
\end{tabular}

Bilich e Silva não falam qual função de preferência utilizaram e nem quais critérios foram maximizados ou minimizados na escolha de seleção deles (axiomas de Roy). Considerando o cenário 1 (figura 1), essa informação se torna relevante na etapa de discussão das diferenças apresentadas e comparação de cenários. 


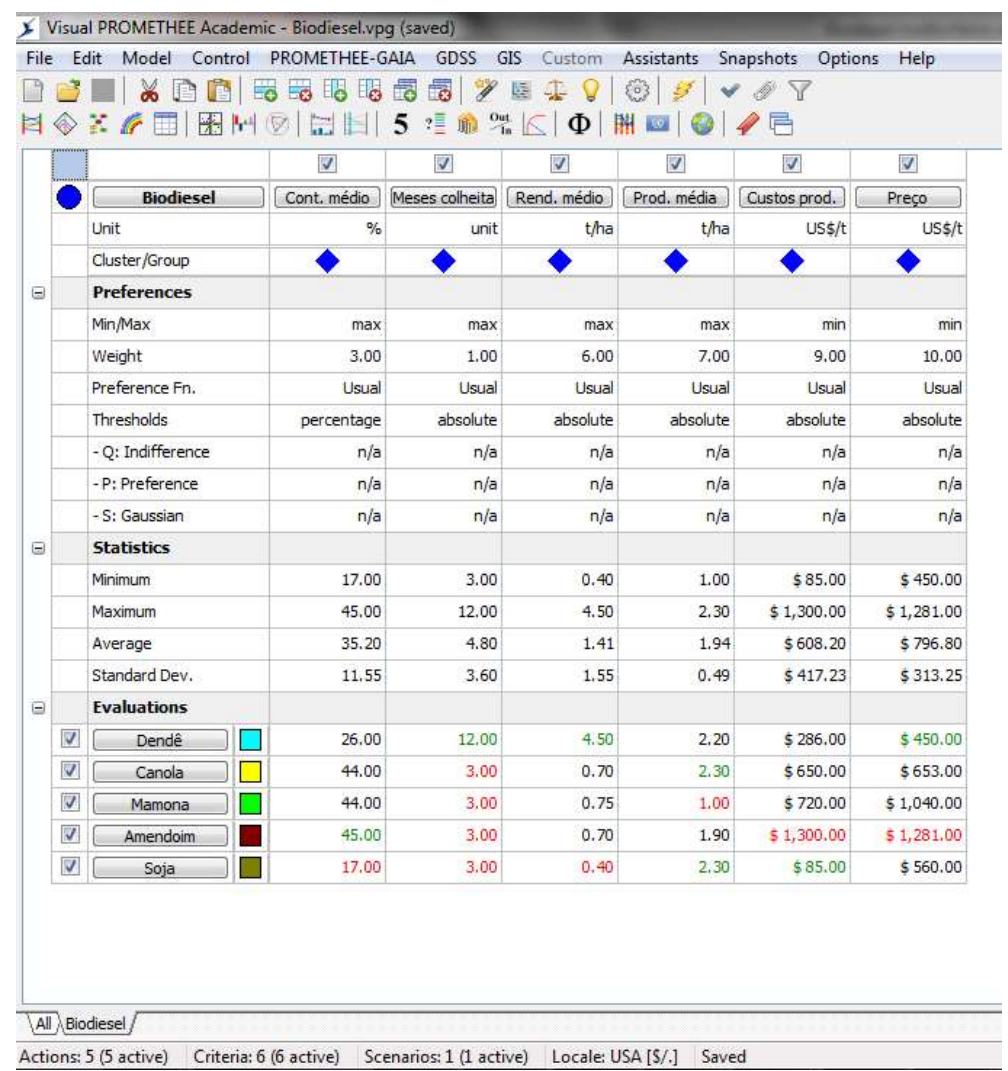

Figura 1: Cenário 1 com as alternativas e critérios definidos. Fonte: Promethee Academic

Essa figura mostra a completa entrada de dados: definição das alternativas, escolhas de critérios e pesos, função de preferência, valores das alternativas em relação aos critérios, etc. A tabela 15 mostra a classificação gerada pelo PROMETHEE para o cenário 1.

Tabela 15: Classificação do cenário 1.

\begin{tabular}{|l|l|l|l|l|}
\hline Classificação & Alternativas & $\Phi$ & $\Phi+$ & $\Phi-$ \\
\hline $\mathbf{1}$ & Dendê & 0.5556 & 0.7778 & 0.2222 \\
\hline $\mathbf{2}$ & Soja & 0.2778 & 0.6042 & 0.3264 \\
\hline $\mathbf{3}$ & Canola & 0.1181 & 0.4931 & 0.3750 \\
\hline $\mathbf{4}$ & Mamona & -0.3611 & 0.2986 & 0.6597 \\
\hline $\mathbf{5}$ & Amendoim & -0.5903 & 0.1736 & 0.7639 \\
\hline
\end{tabular}

Serão utilizados dados mais abrangentes no cenário 2 (figura 2), principalmente em relação aos custos de produção e preço dos óleos retirados de http://www.biomercado.com.br/, https://www.conab.gov.br/ e https://www.embrapa.br/. As alternativas estratégicas serão as mesmas consideradas no cenário 1 com a inclusão de babaçu e girassol. Os critérios utilizados, função de preferência (I) e grau de otimização serão os mesmos do cenário 1 com o acréscimo da demanda por área cultivada e pesos associados diferentes (tabela 17). As datas das cotações nos principais mercados: nacional (Brasil) e internacional (Argentina, EUA, Índia, Malásia e Rotterdam) dos preços dos óleos utilizados na tabela 16 referem-se ao período de 2016-2017. 
Tabela 16: Alternativas e critérios do Cenário 2.

\begin{tabular}{|l|l|l|l|l|l|l|l|l|}
\hline Espécie & $\begin{array}{l}\text { Origem do } \\
\text { óleo }\end{array}$ & $\begin{array}{l}\text { Cont. de } \\
\text { óleo [\%] }\end{array}$ & $\begin{array}{l}\text { Meses de } \\
\text { colheita }\end{array}$ & $\begin{array}{l}\text { Dem. área } \\
\text { cult. [há] }\end{array}$ & $\begin{array}{l}\text { Rend. em } \\
\text { óleo [t/há] }\end{array}$ & $\begin{array}{l}\text { Prod. } \\
\text { Média } \\
\text { [t/há] }\end{array}$ & $\begin{array}{l}\text { Custos } \\
\text { Produção } \\
\text { [US\$\$/t] }\end{array}$ & $\begin{array}{l}\text { Preço óleos } \\
\text { [US\$/t] }\end{array}$ \\
\hline $\begin{array}{l}\text { Amendoim (Arachis } \\
\text { Hypogaea) }\end{array}$ & Grão & 45 & 3 & 1420 & 0,7 & 1,9 & 1100 & 1150 \\
\hline $\begin{array}{l}\text { Babaçu (Attalea } \\
\text { speciosa M.) }\end{array}$ & Amêndoa & 66 & 12 & 8900 & 0,6 & 1,8 & 300 & 1363 \\
\hline $\begin{array}{l}\text { Colza ou Canola } \\
\text { Brassica napus) }\end{array}$ & Grão & 44 & 3 & 1430 & 0,7 & 2,3 & 420 & 717 \\
\hline $\begin{array}{l}\text { Dendê (Elaeis } \\
\text { Guineensi N.) }\end{array}$ & Amêndoa & 24 & 12 & 200 & 4,5 & 2,2 & 254 & 474 \\
\hline $\begin{array}{l}\text { Girassol (Helianthus } \\
\text { annuus) }\end{array}$ & Grão & 43 & 3 & 1090 & 1,0 & 1,3 & 1431 & 1100 \\
\hline $\begin{array}{l}\text { Mamona (Ricinus } \\
\text { communis) }\end{array}$ & Grão & 45 & 3 & 1400 & 0,75 & 1,0 & 573 & 1224 \\
\hline Soja (Glycine max) & Grão & 17 & 3 & 2850 & 0,4 & 2,3 & 125 & 618 \\
\hline
\end{tabular}

Fonte: Elaborada a partir de Cardoso et al (2012), Embrapa, Biomercado, Conab e Cadernos NAE.

Tabela 17: Critérios, otimização e pesos do cenário 2.

\begin{tabular}{|l|l|l|}
\hline Critérios & Otimização & Pesos associados \\
\hline C1 & Max & 7 \\
\hline C2 & Max & 5 \\
\hline C3 & Max & 7,5 \\
\hline C4 & Max & 8,5 \\
\hline C5 & Min & 10 \\
\hline C6 & Min & 10 \\
\hline C7 & Min & 8 \\
\hline
\end{tabular}

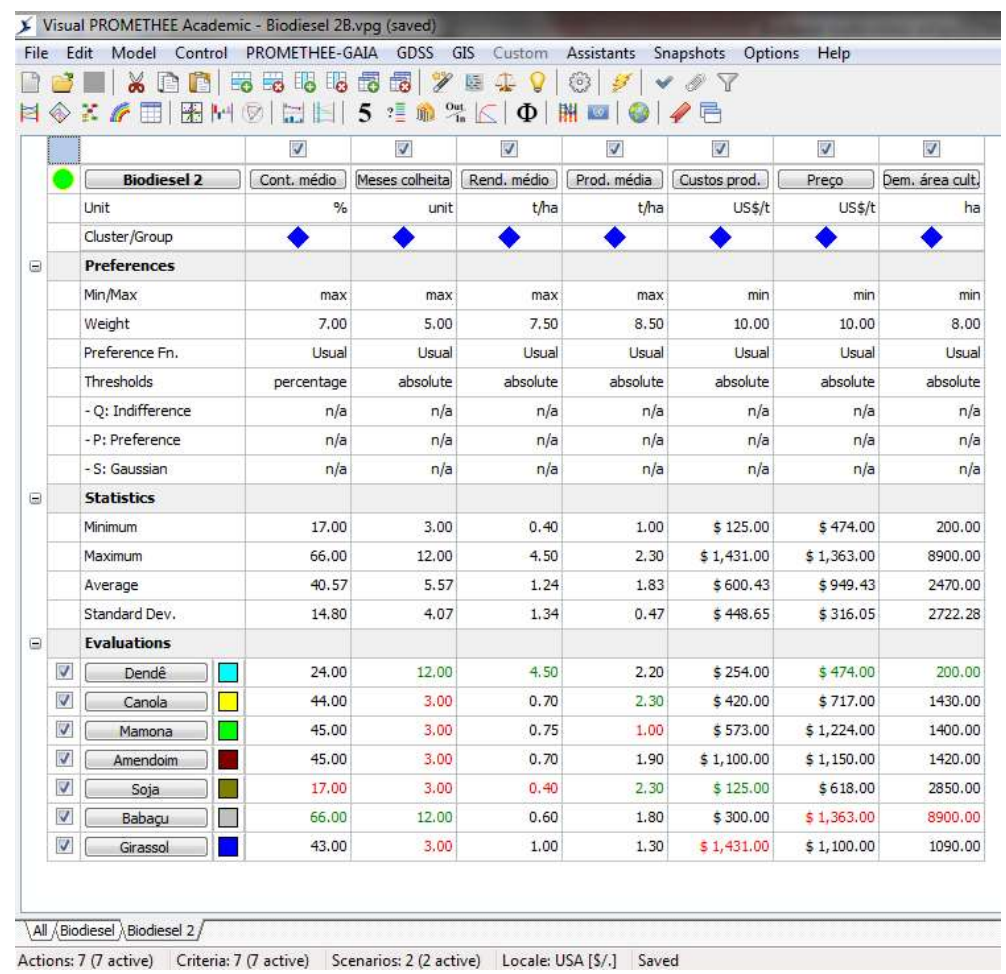

Figura 2: Cenário 2 com as alternativas e critérios definidos. Fonte: Promethee Academic

Tabela 18: Classificação do cenário 2.

\begin{tabular}{|l|l|l|l|l|}
\hline Classificação & Alternativas & $\boldsymbol{\Phi}$ & $\boldsymbol{\Phi +}$ & $\boldsymbol{\Phi}-$ \\
\hline $\mathbf{1}$ & Dendê & 0.6161 & 0.8006 & 0.1845 \\
\hline $\mathbf{2}$ & Canola & 0.0863 & 0.4896 & 0.4033 \\
\hline $\mathbf{3}$ & Soja & 0.0402 & 0.4777 & 0.4375 \\
\hline $\mathbf{4}$ & Girassol & -0.1667 & 0.3869 & 0.5536 \\
\hline $\mathbf{5}$ & Amendoim & -0.1682 & 0.3646 & 0.5327 \\
\hline $\mathbf{6}$ & Babaçu & -0.2024 & 0.3914 & 0.5938 \\
\hline $\mathbf{7}$ & Mamona & -0.2054 & 0.3571 & 0.5625 \\
\hline
\end{tabular}




\section{DISCUSSÃO}

A comparação dos cenários será feita por meio de observações das classificações obtidas por cada cenário. O cenário considerado por Bilich e Silva em 2006 (tabela 19), apresentou algumas modificações em relação ao cenário 1 utilizado no presente trabalho.

Tabela 19: Classificação do cenário gerado por Bilich e Silva.

\begin{tabular}{|l|l|l|l|l|}
\hline Classificação & Alternativas & $\boldsymbol{\Phi}$ & $\boldsymbol{\Phi}$ & $\boldsymbol{\Phi}-$ \\
\hline $\mathbf{1}$ & Soja & 0.50 & 0.72 & 0.22 \\
\hline $\mathbf{2}$ & Dendê & 0.25 & 0.63 & 0.38 \\
\hline $\mathbf{3}$ & Canola & -0.12 & 0.38 & 0.49 \\
\hline $\mathbf{4}$ & Mamona & -0.17 & 0.40 & 0.56 \\
\hline $\mathbf{5}$ & Amendoim & -0.47 & 0.24 & 0.70 \\
\hline
\end{tabular}

Fonte: Elaborada a partir de Bilich et al. (2006).

A figura 3 revela o caminho da preferência das alternativas depois de passar da etapa de classificação pelo programa PROMETHEE I (fluxos parciais). A distância entre as alternativas também mostra a diferença dos fluxos envolvidos na comparação.

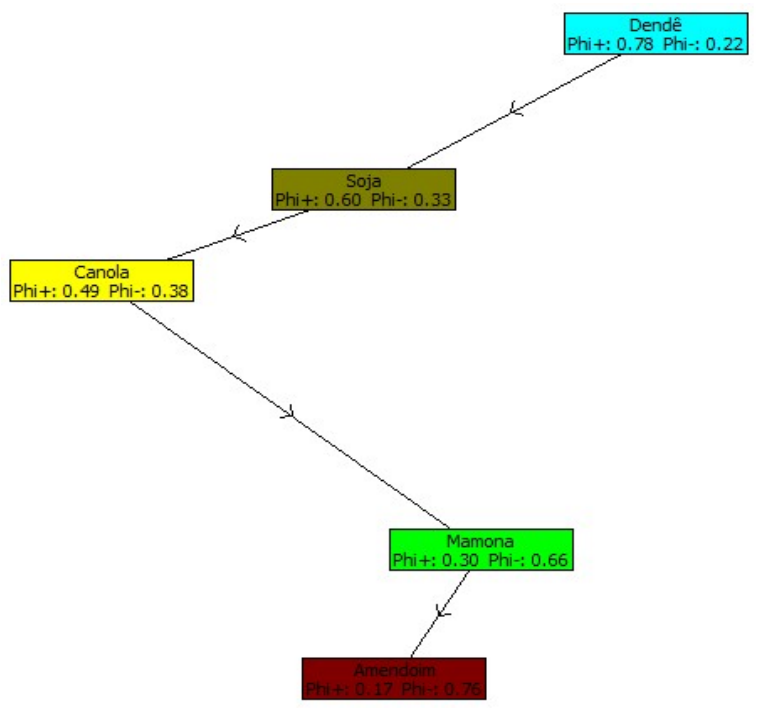

Figura 3: Rede de preferência do cenário 1. Fonte: Promethee Academic

Fazendo a comparação entre o ranking do cenário considerado por Bilich et al. (2006) da tabela 19 e o ranking do cenário 1 da tabela 15, observa-se que: soja e dendê trocaram de posições com as demais alternativas permanecendo nas mesmas, apresentando valores diferentes em seus fluxos líquidos. O porquê dessa diferença surge como questão a ser respondida.

Bilich e Silva utilizaram o software Decision Lab baseado na metodologia multicritério PROMETHEE, assim como o Visual PROMETHEE 1.4 - Academic Version. Apesar das diferenças estéticas (interface gráfica) de cada programa, ambos usam a mesma metodologia, em teoria para valores iguais de alternativas e critérios os resultados gerados deveriam ser os mesmos. Mas como já mencionado antes, Bilich e Silva não falam quais funções de preferências foram usadas em seus critérios e respectiva otimização dos mesmos (maximização ou minimização). Então as diferenças apresentadas nos rankings aconteceram devido a esses dois casos (funções de preferência e/ou otimização diferentes) mencionados acima. A figura 4 mostra a rede de preferência do cenário 2 . 


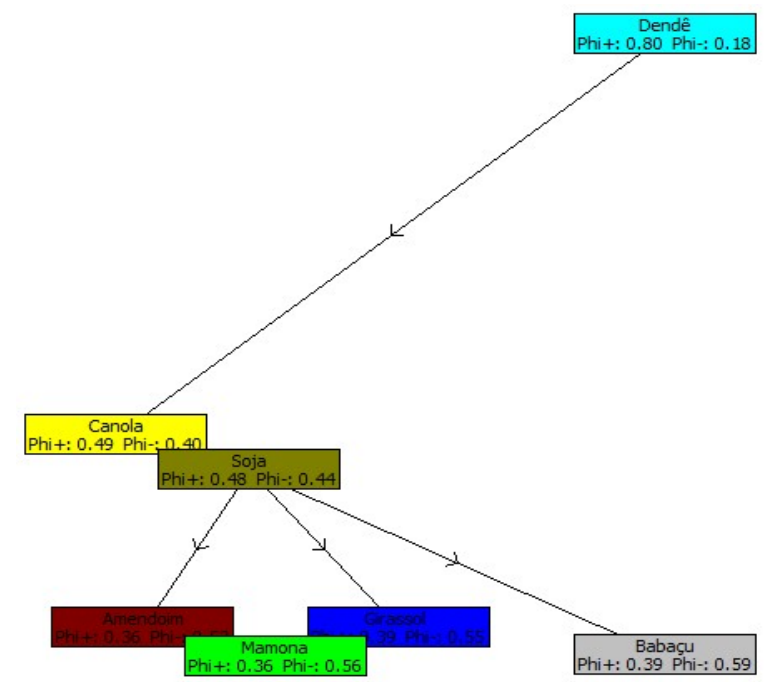

Figura 4: Rede de preferência do cenário 2. Fonte: Promethee Academic

A representação espacial das alternativas em relação aos critérios para integração dos resultados nos Planos Gaia mostra para onde está tendendo o Eixo de Decisão (em vermelho na figura abaixo). Ou seja, qual(is) critério(s) vão pesar/influenciar mais no processo de escolha das alternativas em relação aos critérios envolvidos na análise e consequentemente na classificação final dos resultados.

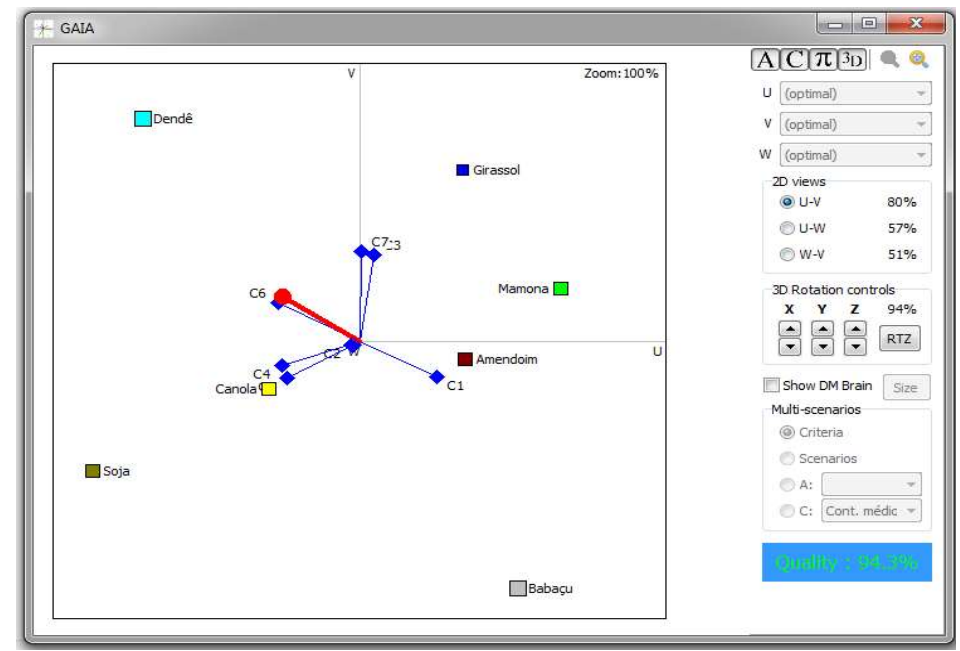

Figura 5: Visualização do Plano Gaia no cenário 2. Fonte: Promethee Academic

Comparando os rankings gerados nos cenários 1 e 2 (tabelas 15 e 18), tem-se as seguintes informações abaixo: Rede de preferência mais parelha no cenário 2 (fig. 4) e espaçada no cenário 1 (fig. 3); Mudança no rank (troca de posições entre soja e canola, amendoim se mantendo na quinta posição e mamona caindo para última posição); Girassol aparecendo na quarta posição e babaçu na sexta; Melhora das performances do dendê, mamona e amendoim com piora da canola e soja. Uma forma de ajudar a melhorar essa comparação é focar nos resultados obtidos através dos fluxos líquidos de sobreclassificação apresentados por cada cenário 1 e 2 (tabela 20).

Tabela 20: Fluxos obtidos nos cenários 1 e 2.

\begin{tabular}{|l|l|l|}
\hline Alternativas & $\Phi$ & Classificação Geral \\
\hline Dendê 2 & 0.6161 & 1 \\
\hline Dendê 1 & 0.5556 & 2 \\
\hline
\end{tabular}




\begin{tabular}{|l|l|l|}
\hline Soja 1 & 0.2778 & 3 \\
\hline Canola 1 & 0.1181 & 4 \\
\hline Canola 2 & 0.0863 & 5 \\
\hline Soja 2 & 0.0402 & 6 \\
\hline Girassol 2 & -0.1667 & 7 \\
\hline Amendoim 2 & -0.1682 & 8 \\
\hline Babaçu 2 & -0.2024 & 9 \\
\hline Mamona 2 & -0.2054 & 10 \\
\hline Mamona 1 & -0.3611 & 11 \\
\hline Amendoim 1 & -0.5903 & 12 \\
\hline
\end{tabular}

O dendê do cenário 2 se saiu melhor na classificação final, mas em compensação tivemos três oleaginosas do cenário 1 na segunda, terceira e quarta colocação. Sendo elas respectivamente: dendê, soja e canola. Verifica-se pelo software PROMETHEE 1.4 que o método favorece um completo ranking de ações sempre baseado em um fluxo líquido de sobreclassificação, facilitando incluir preferências e indiferenças em uma pré-ordem completa entre as alternativas e critérios estabelecidos. Deste estudo direciona-se para a real competitividade do Brasil na produção de biodiesel, seu papel no fortalecimento da base agroindustrial brasileira e no incremento da matriz energética com sustentabilidade, impactando na geração de empregos e benefícios ambientais. É importante ainda salientar que o biodiesel independente da matéria prima e/ou rota tecnológica é introduzido no mercado brasileiro de combustíveis com especificação única atendendo os padrões de qualidade estabelecidos pela ANP. Padrões esses em conformidade com as normas internacionais de biocombustíveis.

A decisão final sempre vai caber ao decisor podendo englobar o uso de uma ou mais alternativas de acordo com as vantagens e desvantagens apresentadas no modelo de AMD do empreendimento em questão, buscando a melhor forma de otimização do processo geral como um todo. Desta forma, pode-se enfatizar que a abordagem multicritério é, por natureza, multidisciplinar priorizando a convergência de metas no processo de gestão.

\section{CONCLUSÕES}

Dentre as culturas de oleaginosas com potencial para a produção do biodiesel brasileiro consideradas nos cenários 1 e 2, dendê teve o melhor desempenho na classificação em ambos os cenários com base nos critérios investigados em cada um desses cenários. Para o cenário 1 a classificação final ficou assim: dendê; soja; canola; mamona; amendoim. Já no cenário 2 a classificação final foi: dendê; canola; soja; girassol; amendoim; babaçu; mamona.

O uso dos métodos multicritérios como importante ferramenta no auxílio da escolha de melhor oleaginosa para a produção do biodiesel visa resolver, sobretudo, à gestão de conflitos onde os resultados demonstrados permitem visualizar e analisar questões relevantes da sistemática de decisão e poderão auxiliar os tomadores de decisão no aprimoramento das suas atividades no setor agroindustrial.

Um dos fatores relevantes na metodologia multicritério, além da sua versatilidade em se adaptar aos diversos tipos de problemas com temas variados (econômicos, ambientais, sociais, etc), é a capacidade de fazer com que atores (decisores, analistas e especialistas) de diferentes áreas do conhecimento, conversem 
entre si na resolução de um problema que pode ser ou não de natureza multidisciplinar, utilizando uma linguagem universal que vai passar a ser o método multicritério escolhido ou modelo multicritério. Essa representação será cada vez melhor se isso de fato acontecer, todos têm de ser respeitados na preparação do processo de decisão.

\section{REFERÊNCIAS}

ALVARENGA, M. A. J.; YOUNG, C. E. F.. Produção de biodiesel no Brasil, inclusão social e ganhos ambientais. In: ENCONTRO LATINO-AMERICANO DE ECONOMIA DA ENERGIA, 4. Anais. Montevidéu: Aladee, 2013.

BARBA-ROMERO, S.; POMEROL, J. C.. Decisiones Multicriterio: Fundamentos Teóricos e Utilización Práctica. Alcalá: Colección de Economia, 1997.

BILICH, F.; SILVA, R. DA S.. Análise multicriterio da produção de biodiesel. In: SIMPÓSIO DA ENGENHARIA DE PRODUÇÃO, 13. Anais. Bauru: Unesp, 2006.

BRANS, J. P.; MARESCHAL, B.. PROMÉTHÉE-GAIA: une méthodologie $d^{\prime}$ aide à la décision en présence de critères multiples. 1 ed. Bruxelles: Ellipses, 2002.

BRANS, J. P.; VINCKE, P.; MARESCHAL, B.. How to select and how to rank projects: The PROMETHEE method. European Journal of Operational Research, Netherlands, v.24, n.2, p.228-238, 1986. DOI: https://doi.org/10.1016/03772217(86)90044-5

BRASIL. Cadernos NAE / Núcleo de Assuntos Estratégicos da Presidência da República n.2. Brasília: NAE, 2005.

BRASIL. Lei n.11.097:Dispõe sobre a introdução do biodiesel na matriz energética brasileira; altera as Leis ns. 9.478, de 6 de agosto de 1997, 9.847, de 26 de outubro de 1999 e 10.636, de 30 de dezembro de 2002; e dá outras providências. Brasília: DOU, 2005.

BRASIL. Lei n.13.263:Altera a Lei n.13.033, de 24 de setembro de 2014, para dispor sobre os percentuais de adição de biodiesel ao óleo diesel comercializado no território nacional. Brasília: DOU, 2016.

BRASIL. Lei n.45:Dispõe sobre a especificação do biodiesel contida no Regulamento Técnico ANP no 3 de 2014 e as obrigações quanto ao controle da qualidade a serem atendidas pelos diversos agentes econômicos que comercializam o produto em todo o território nacional. Brasília: DOU, 2014.

CARDOSO, B. F.; NASCIMENTO, J. S.; ARAÚJO, A. F. V. A.; RODRIGUES, W.; OLIVEIRA, T. J. A. O.. Análise Multicritério na seleção de oleaginosas na cadeia de produção de Biodiesel. Revista de Economia Agrícola, São Paulo, v.59, n.1, p.97-107, 2012.

CASTRILLÓN, A. M. G.; RAMÍREZ, S. Q.. Propuesta metodológica para la evaluación del portafolio de proyectos: caso de estudio 'oleaginosas promisoras'. I+D Revista de Investigaciones, Colômbia, v.10, n.2, p.26-39, 2017.

CHAVES, M. C. C.; GOMES, C. F. S.. Avaliação de biocombustíveis utilizando o apoio multicritério à decisão.
Production, São Paulo, v.24, n.3, p.495-507, 2014. DOI: http://dx.doi.org/10.1590/S0103-65132013005000035

CLÍMACO, J.; VALLE, R.. Apoio Multicritério à Decisão e Desenvolvimento Sustentável. In: CONGRESSO LATINOIBEROAMERICANO DE PESQUISA OPERACIONAL, 16. Anais. Rio de Janeiro: FGV, 2012.

CORRAL, S.; NUEZ, D. L. N.; LARA, D. R. M. L.. Integrated assessment of biofuel production in arid lands: Jatropha cultivation on the island of Fuerteventura. Renewable and Sustainable Energy Reviews, United Kingdom, v.52, n.1, p.41-53, 2015. DOI: https://doi.org/10.1016/j.rser.2015.07.070

DELAI, J. M.; SANTOS, R. F.; SANTOS, M. A.; ANZOATEGUI, R.; CARMO, E. R. C.. Biodiesel: uma análise da produção no Brasil. Acta Iguazu, Cascavel, v.3, n.1, p.109-123, 2014.

FERREIRA, M. O.; MOURA, K. H. L.; SALES, R. S. P.. Seleção de oleaginosas para produção de biodiesel no agreste pernambucano com a aplicação dos métodos multicritérios para a decisão. In: ENCONTRO NACIONAL DE ENGENHARIA DE PRODUÇÃO, 30. Anais. São Carlos: UFSCar, 2010.

FLAMENT, M.. Glossário multicritério. Red Iberoamericana de Evaluación y Decisión Multicritério. Madri: UNESCO, 1999.

GARTNER, I. R.. Avaliação ambiental de projetos em bancos de desenvolvimento nacionais e multilaterais: evidências e propostas. 2 ed. Brasília: Universa, 2008.

GOMES JÚNIOR, S. F.; SOARES DE MELLO, J. C. C. B.. Emprego de Métodos Ordinais Multicritério na análise do campeonato mundial de fórmula 1. In: SIMPÓSIO DE PESQUISA OPERACIONAL E LOGÍSTICA DA MARINHA. Anais. Rio de Janeiro: EGN, 2007.

GOMES, C. F. S.; COSTA, H. G.. Aplicação de métodos multicritério ao problema de escolha de modelos de pagamento eletrônico por cartão de crédito. Production, São Paulo, v.25, n.1, p.54-68, 2015. DOI: http://dx.doi.org/10.1590/S0103-65132013005000068

GOMES, C. F. S.; MAIA, A. C. C.. Ordenação de alternativas de biomassa utilizando o apoio multicritério à decisão. Produção, São Paulo, v.23, n.3, p.488-499, 2013. DOI: http://dx.doi.org/10.1590/S0103-65132013005000005

GOMES, E. G.. Integração entre Sistemas de Informação Geográfica e Métodos Multicritério no Apoio à Decisão Espacial. Dissertação (Mestrado em Engenharia) Universidade Federal do Rio de Janeiro, Rio de Janeiro, 1999. 
GOMES, L. F. A. M.; ARAYA, M. C. G.; CARIGNANO, C.. Tomada de decisões em cenários complexos. São Paulo: Thompson, 2004.

GUARDIOLA, J. F. H.; LOPES, R. F.; SOARES DE MELLO, J. C. C. B.; SILVA, F. C. S.. Modelo de Análise Multicritério na Avaliação de diferentes cultivos na Produção de Biodiesel. In: SIMPÓSIO BRASILEIRO DE PESQUISA OPERACIONAL, 49. Anais. Blumenau: FURB, 2017.

HARRIS, R.. Introduction to Decision Making. VirtualSalt, California, v.1, n.4, p.1-3, 2012

HUANG, I. B. H.; KEISLER, J.; LINKOV, I.. Multi-criteria decision analysis in environmental sciences: Ten years of applications and trends. Science of The Total Environment, Netherlands, v.409, n.19, p.3578-3594, 2011. DOI: https://doi.org/10.1016/i.scitotenv.2011.06.022

KEENEY, R.; RAIFFA, H.. Decision with Multiple Objectives: preferences and value tradeoffs. New York: John Wiley \& Sons, 1976.

KHALIL, C. N.. As tecnologias de produção de biodiesel. 0 futuro da indústria: biodiesel, Brasília, v.14, n.1, p.83-90, 2006.

MORAIS, D. C.; ALMEIDA, A. T.. Modelo de decisão em grupo para gerenciar perdas de água. Pesquisa Operacional, Rio de Janeiro, v.26, n.3, p.567-584, 2006. DOI: http://dx.doi.org/10.1590/S0101-74382006000300007

MUTIKANGA, H. E.; SHARMA, S. K.; VAIRAVAMOORTHY, K.. Multi-criteria Decision Analysis: a strategic planning tool for water loss management. Water Resources Manage, Holanda, v.25, n.1, p.3947-3969, 2011. DOI: https://doi.org/10.1007/s11269-011-9896-9

NARAYANAN, D.; ZHANG, Y.; MANNAN, M. S.. Engineering for Sustainable Development (ESD) in Bio-Diesel Production. Process Safety and Environmental Protection, Texas, v.85, n.5, p.349-359, 2007. DOI: https://doi.org/10.1205/psep07016

NEWLANDS, N. K.; SMITH, L. T.. Biodiesel from Oilseeds in the Canadian Prairies and Supply-Chain Models for Exploring Production Cost Scenarios: A Review. ISRN Agronomy, New York, v.2012, n.1, p.1-11, 2012. DOI: http://dx.doi.org/10.5402/2012/980621

NWOKOAGBARA, E.; OLALEYE, A. K.; WANG, M.. Biodiesel from Microalgae: The Use of Multi-Criteria Decision Analysis for Strain Selection. Fuel, England, v.159, n.1, p.241-249, 2015. DOI: https://doi.org/10.1016/j.fuel.2015.06.074

OLIVEIRA, F. C. C.; SANTOS, W. L. P.; SUAREZ, P. A.. Biodiesel: Possibilidades e Desafios. Química Nova na Escola, São Paulo, v.28, n.1, p.3-8, 2008.
PRADO, E. A.; ZAN, R. A.; GOLFETTO, D. C.; SCHWADE, V. D. Biodiesel: um tema para uma aprendizagem efetiva. In: CONGRESSO BRASILEIRO DE EDUCAÇÃO EM ENGENHARIA, 34. Anais. Passo Fundo: UPF, 2006

RABELO, R. S.; PLÀCIDO, G. R.; TININIS, A. G.; TININIS, C. R. C. S.. Estudo da viabilidade de oleaginosas do Cerrado goiano com vistas à produção de biodiesel por meio da metodologia multicritério. In: SIMPÓSIO NACIONAL DE BIOCOMBUSTÍVEIS, 2. Anais. Recife: UFPE, 2009.

REN, J.; MANZARDO, A.; MAZZI, A.; FEDELE, A.; SCIPIONI, A.. Emergy Analysis and Sustainability Efficiency Analysis of Different Crop-Based Biodiesel in Life Cycle Perspective. The Scientific World Journal, London, v.2013, n.1, p.1-12, 2013. DOI: http://dx.doi.org/10.1155/2013/918514

ROY, B.. Classement et choix en presence de points de vue multiples: la methode ELECTRE. Lausanne: Presses Polytechiniques et Universitaires Romandes, 1968.

ROY, B.; BOUYSSOU, D.. Aid Multicritère à la decision. Paris: Economica, 1993.

SAKTHIVEL, G.; ILANGKUMARAN, M.; GAIKWAD, A.. A hybrid multi-criteria decision modeling approach for the best biodiesel blend selection based on ANP-TOPSIS analysis. Ain Shams Engineering Journal, Egypt, v.6, n.1, p.239-256, 2015. DOI: https://doi.org/10.1016/i.asej.2014.08.003

SCOTT, J. A.; HO, W.; DEY, P. K.. A review of multi-criteria decision-making methods for bioenergy systems. Energy, United Kingdom, v.42, n.1, p.146-156, 2012. DOI: https://doi.org/10.1016/j.energy.2012.03.074

SILVA, V. B. DE S.; SCHRAMM, F.; CARVALHO, H. R. C. DE C.. $O$ uso do método PROMETHEE para seleção de candidatos à bolsa-formação do Pronatec. Production, São Paulo, v.24, n.3, p.548-558, 2014. DOI: http://dx.doi.org/10.1590/S0103$\underline{65132013005000048}$

SOARES DE MELLO, J. C. C. B.; GOMES, E. G.; LETA, F. R.; PESSOLANI, R. V. B.. Conceitos básicos do Apoio Multicritério à Decisão e sua aplicação no projeto Aerodesign. Engevista, Niterói, v.5, n.8, p.22-35, 2003.

TSOUKIÀS, A.. From decision theory to decision aiding methodology. European Journal of Operational Research, Europa, v.187, n.1, p.138-161, 2008. DOI: https://doi.org/10.1016/j.ejor.2007.02.039

VILAS BOAS, C. L.. Modelo Multicritérios de Apoio à Decisão aplicado ao uso múltiplo de reservatórios: estudo da barragem do Ribeirão João Leite. Dissertação (Mestrado em Gestão Econômica do Meio Ambiente) - Universidade de Brasília, Brasília, 2006.

A CBPC - Companhia Brasileira de Produção Científica (CNPJ: 11.221.422/0001-03) detém os direitos materiais desta publicação. Os direitos referem-se à publicação do trabalho em qualquer parte do mundo, incluindo os direitos às renovações, expansões e disseminações da contribuição, bem como outros direitos subsidiários. Todos os trabalhos publicados eletronicamente poderão posteriormente ser publicados em coletâneas impressas sob coordenação da Sustenere Publishing, da Companhia Brasileira de Produção Científica e seus parceiros autorizados. Os (as) autores (as) preservam os direitos autorais, mas não têm permissão para a publicação da contribuição em outro meio, impresso ou digital, em português ou em tradução. 